\title{
THE 3MV MULTI-ELEMENT AMS IN XI'AN, CHINA: UNIQUE FEATURES AND PRELIMINARY TESTS
}

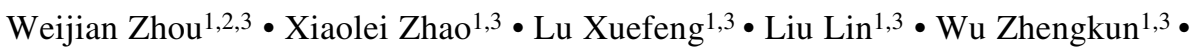 \\ Cheng Peng ${ }^{1} \cdot$ Zhao Wengnian $^{3} \bullet$ Huang Chunhai ${ }^{3}$
}

\begin{abstract}
A 3MV multi-element accelerator mass spectrometer (AMS) has been installed in Xi' an, China, and preliminary tests have been completed. The results of both background and precision tests for 4 nuclides are $3.1 \times 10^{-16}, 0.2 \%\left({ }^{14} \mathrm{C}\right)$; $1.8 \times 10^{-14}, 1.4 \%\left({ }^{10} \mathrm{Be}\right) ; 2.3 \times 10^{-15}, 1.14 \%\left({ }^{26} \mathrm{Al}\right)$; and $2.0 \times 10^{-14}, 1.75 \%\left({ }^{129} \mathrm{I}\right)$. The unique features of this facility are the newly developed ion source accepting solid and $\mathrm{CO}_{2}$ samples; the specially designed low-energy injector, including a "beam blanking unit" and "Q-snout"; the acceleration tube structure with the combined magnetic and electrostatic suppression; and the function of the slit stabilization in the post-acceleration system. These features are discussed in terms of the end-user's point of view.
\end{abstract}

\section{INTRODUCTION}

The Xi' an 3MV accelerator mass spectrometer (AMS) in the joint AMS laboratory of the Institute of Earth Environment and JiaoTong University (Zhou et al. 2005) is the 4th AMS system designed by High Voltage Engineering Europa (HVEE) that includes a sequential-injection system for the isotopes using a retarding electrostatic field (i.e. a "bouncer") (Gottdang et al. 1997, 1999). Unlike the 3 preceding HVEE systems in JAERI (Aramaki et al. 2000), Lecce (Calcagnile et al. 2004), and INFN (PA Mando, personal communication, 2004), this facility is a multi-element system with a single beam line dedicated to AMS applications. The Xi' an 3MV AMS is shown in Figure 1, and its main parts are listed in Table 1.

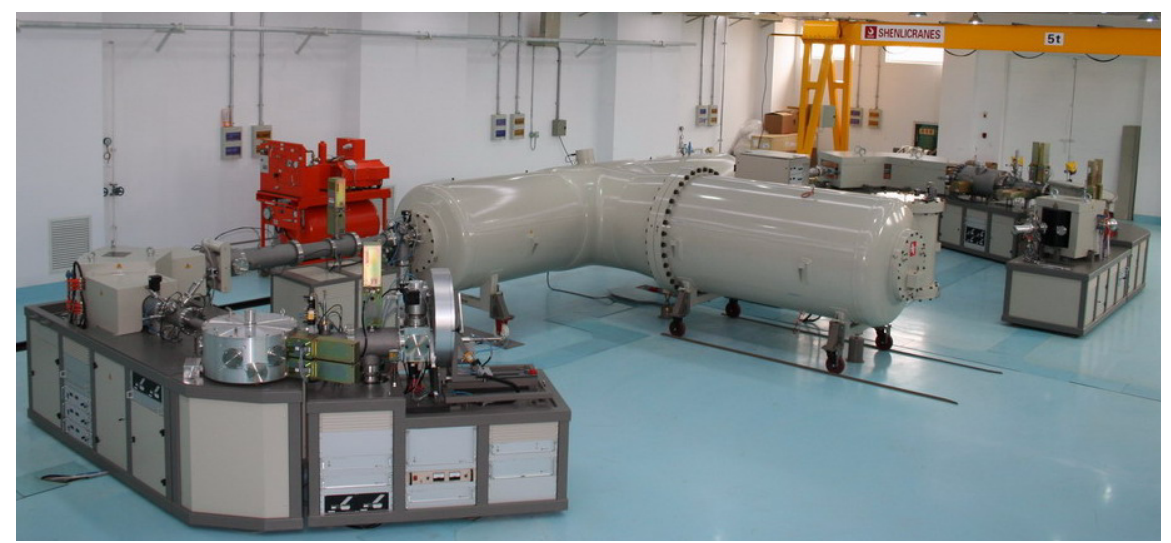

Figure 1 The 3MV multi-element AMS in Xi'an, China

At the end of 2003, a contract was signed with HVEE for a $3 \mathrm{MV}$ multi-element $\left({ }^{10} \mathrm{Be},{ }^{14} \mathrm{C},{ }^{26} \mathrm{Al}\right.$, and ${ }^{129}$ I) AMS system based on the Tandetron system. The pre-shipment tests were carried out at HVEE in September 2004, and the equipment was shipped to Xi' an shortly thereafter. During the pre-shipment tests, several checks were carried out on the major components: the $3 \mathrm{MV}$ terminal voltage was maintained for $4 \mathrm{hr}$ without sparking; the ${ }^{14} \mathrm{C}$ and ${ }^{10} \mathrm{Be}$ ions were detected; while testing, the $\mathrm{X}$-ray

\footnotetext{
${ }^{1}$ State Key Lab of Loess and Quaternary Geology, Institute of Earth Environment, Xi'an 710075, China.

${ }^{2}$ Corresponding author. Email: weijian @loess.llqg.ac.cn.

${ }^{3}$ Xi' An Jiaotong University, Xi' an 710049, China.
} 
Table 1 Major components of the HVEE 3MV multi-element AMS in Xi'an.

\begin{tabular}{ll}
\hline Ion source & Cs sputter negative ion source \\
& SO-110 accepting gaseous or 50 solid targets \\
\hline Low-energy & $54^{\circ}$ spherical electrostatic deflector $(R=470 \mathrm{~mm})$ \\
Injector & $90^{\circ}$ bouncer magnet with double focusing $(R=400 \mathrm{~mm})$ \\
& Beam blanking unit \\
& Q-snout \\
\hline Tandetron & $3 \mathrm{MV}$ terminal with gas stripper \\
& Acceleration tube with combined magnetic and electrostatic suppression \\
\hline High-energy & $115^{\circ}$ analyzing magnet $(R=1200 \mathrm{~mm})$ \\
analyzing system & $65^{\circ}$ cylindrical electrostatic deflector $(R=1700 \mathrm{~mm})$ \\
& $30^{\circ}$ analyzing magnet $(R=1500 \mathrm{~mm})$ \\
& $\mathrm{Slit}$ stabilization system \\
& $\mathrm{Si}_{3} \mathrm{~N}_{4}$ foil assembly for ${ }^{10} \mathrm{Be}$ measurement \\
\hline Detector & Gas ionization chamber \\
\hline Control system & High-level and low-level control with all signals transferred by fiber-optic lines \\
\hline
\end{tabular}

radiation was well below $2 \mu \mathrm{S} / \mathrm{hr}$ at $1 \mathrm{~m}$ from the tank wall; and finally, the tank was opened to verify the condition of the tandem accelerator.

This Xi' an 3MV AMS facility began installation in early June 2005, and the preliminary acceptance tests have been recently carried out. This paper will describe the test results and features of the facility in terms of the end-user's points of view.

\section{RESULTS OF THE PRELIMINARY TESTS}

In addition to the retest of the $3 \mathrm{MV}$ terminal voltage stability for $4 \mathrm{hr}$ (3.3 MV during conditioning), acceptance tests mainly focused on tests of the background for isotope ratio and precision at the modern isotope ratio for 4 radionuclides $\left({ }^{10} \mathrm{Be},{ }^{14} \mathrm{C},{ }^{26} \mathrm{Al}\right.$, and $\left.{ }^{129} \mathrm{I}\right)$ operating at a terminal voltage of 2.5-2.6 MV. When the precision tests were performed, the beam currents for the above 4 isotopes (analyzed currents before injection into the tandem) were $1.7 \mu \mathrm{A}\left(\mathrm{Be}^{-}\right), 38 \mu \mathrm{A}\left(\mathrm{C}^{-}\right), 0.25 \mu \mathrm{A}\left(\mathrm{Al}^{-}\right)$, and $2.5 \mu \mathrm{A}\left(\mathrm{I}^{-}\right)$, respectively. The precision measurements were demonstrated by measuring 12 holders ( 6 for each day) provided by HVEE for modern carbon and 4 holders each for the other 3 isotopes. The test procedures for the determination of both the background and precision were as follows:

1. The AMS machine was operating for at least several hr before data was recorded;

2. After pumping the AMS system down, each sample was sputter-cleaned by exposure to the cesium beam for a period of $\sim 5 \mathrm{~min}$;

3. Data acquisition began in a series of cycling measuring sequence, and each of the datum points represents an accumulation of data taken in individual 30-s collection blocks.

The preliminary results are shown in Table 2.

The background and precision levels achieved for all 4 nuclides, except the background for beryllium, were better than the stated expectations of HVEE at a terminal voltage of 2.5-2.6 MV. It can be seen from ${ }^{14} \mathrm{C}$ precision measurements that the measured precision of ${ }^{14} \mathrm{C} /{ }^{12} \mathrm{C}$ ratios are close to the statistical error, indicating that the AMS system was operating according to specifications. However, this was not the case for the other 3 isotopes, especially the statistical error $(1.56 \%)$ in the ${ }^{26} \mathrm{Al}$ precision measurement, which was much bigger than the precision $(1.14 \%)$ of the ratio ${ }^{26} \mathrm{Al} /{ }^{27} \mathrm{Al}$ 
Table 2 Results of the preliminary tests of the Xi' an AMS.

\begin{tabular}{|c|c|c|c|c|}
\hline Nuclides & Materials & $\begin{array}{l}\text { Isotope } \\
\text { ratio }\end{array}$ & Background & $\begin{array}{l}\text { Precision } \\
\text { (statistical errors) }\end{array}$ \\
\hline $\begin{array}{l}\text { Graphite } \\
\text { (1st day) }\end{array}$ & \multirow{2}{*}{$\begin{array}{l}\text { alfa graphite } \\
\text { (provided by Leibniz-Labor } \\
\text { für Altersbestimmung } \\
\text { und Isotopenforschung, } \\
\text { Christian-Albrechts } \\
\text { Universität of Kiel) }\end{array}$} & $\begin{array}{l}{ }^{14} \mathrm{C} /{ }^{12} \mathrm{C} \\
{ }^{13} \mathrm{C} /{ }^{12} \mathrm{C}\end{array}$ & $\begin{array}{l}3.1 \times 10^{-16} \\
(\sim 65 \mathrm{kyr})\end{array}$ & $\begin{array}{l}0.2 \%(0.208 \%) \text { at } \sim 10^{-12} \\
0.073 \% \text { at } \sim 10^{-12}\end{array}$ \\
\hline $\begin{array}{l}\text { Graphite } \\
\text { (2nd day) }\end{array}$ & & $\begin{array}{l}{ }^{14} \mathrm{C} /{ }^{12} \mathrm{C} \\
{ }^{13} \mathrm{C} /{ }^{12} \mathrm{C}\end{array}$ & & $\begin{array}{l}0.179 \%(0.207 \%) \text { at } \sim 10^{-12} \text {; } \\
0.069 \% \text { at } \sim 10^{-12}\end{array}$ \\
\hline Beryllium & $\begin{array}{l}\mathrm{BeO} \\
\text { (provided by High Voltage } \\
\text { Engineering Europa B.V.) }\end{array}$ & ${ }^{10} \mathrm{Be} /{ }^{9} \mathrm{Be}$ & $1.8 \times 10^{-14}$ & $1.4 \%(0.98 \%)$ at $\sim 10^{-12}$ \\
\hline Aluminum & $\begin{array}{l}\text { commercial powder } \\
\text { (provided by High Voltage } \\
\text { Engineering Europa B.V.) }\end{array}$ & ${ }^{26} \mathrm{Al} /{ }^{27} \mathrm{Al}$ & $2.3 \times 10^{-15}$ & $1.14 \%(1.56 \%)$ at $\sim 10^{-11}$ \\
\hline Iodine & $\begin{array}{l}\mathrm{NaI} \\
\text { (provided by IsoTrace Lab, } \\
\text { University of Toronto) }\end{array}$ & ${ }^{129} \mathrm{I} /{ }^{127} \mathrm{I}$ & $2 \times 10^{-14}$ & $1.75 \%(0.57 \%)$ at $\sim 10^{-10}$ \\
\hline
\end{tabular}

due to the low aluminum current $(0.25 \mu \mathrm{A})$, indicating other sources of error besides pure Poisson statistics. Also, the high ${ }^{14} \mathrm{C}$ precision obtained proves that the bouncer-based sequential injection system is comparable to the recombinator-based simultaneous injection system for ${ }^{14} \mathrm{C}$ measurement. Repeatability of the ${ }^{14} \mathrm{C} /{ }^{12} \mathrm{C}$ ratio during 2 consecutive days was $0.45 \%$, indicating that there may be other sources of error. In addition, because of the reassembling of the equipment on-site, the system function tests were carried out one by one according to the contract.

\section{END-USER'S POINT OF VIEW ON FEATURES OF THE XI'AN 3MV AMS}

\section{lon Source Accepting $\mathrm{CO}_{2}$ and Solid Samples}

The Xi' an AMS adopted a HVEE/Oxford-developed sputter negative ion source (Mous et al. 1998) that directly accepts both $\mathrm{CO}_{2}$ samples and solid samples with 50 samples on the carousel. At present, only the solid samples are used.

The main advantage (Mous et al. 1998) of the HVEE source (Model SO-110) is that the stainless steel source embodiment, including the carousel, is at ground potential during operation, avoiding the need for a large isolation cage. All high-voltage connections to the source, including the highvoltage cable, the $\mathrm{Cs}$ reservoir, the $\mathrm{CO}_{2}$ feed tube, and the cooling lines, are brought together on the source-head insulation flange, keeping to a minimum the space needed for external high-voltage isolation. The source-head can be pulled sideways from the source embodiment, making maintenance easy, and no realignment is needed after a cleaning procedure (Mous et al. 1998).

Compared with the earlier HVEE-made 846B source, an improvement of the source is the smaller holder size. An important change in the source is the removal of the computer-controlled sample movement in the orthogonal direction on the vertical plane, which might affect the crater on the sample surface and introduce fractionation. This concern was increased by the observation that the ratio of ${ }^{13} \mathrm{C} /{ }^{12} \mathrm{C}$ was changing on a long-term basis during the ${ }^{14} \mathrm{C}$ background tests. In order to further explore the crater effect, we measured 2 modern carbon samples (an Oxalic-II acid standard $[\mathrm{NOX}]$ and a previously measured Chinese sugar carbon) on 2 different days to examine the change of the isotope ratio of ${ }^{13} \mathrm{C} /{ }^{12} \mathrm{C}$. These results are shown in both Table 3 and Figure 2. The NOX sam- 
ple was measured from the time after it was exposed to cesium for $5 \mathrm{~min}$, and the Chinese sugar carbon sample was measured for more than $1 \mathrm{hr}$. The different curve shapes of the above 2 samples demonstrate the irregularity of the crater effect. The results show that the relative standard deviation (RSD) of the ${ }^{13} \mathrm{C} /{ }^{12} \mathrm{C}$ isotope ratio deteriorates during a total ${ }^{14} \mathrm{C}$ count from 210,000 counts towards 450,000 counts; the average ratio of ${ }^{13} \mathrm{C} /{ }^{12} \mathrm{C}$ changed by $0.02 \%$.

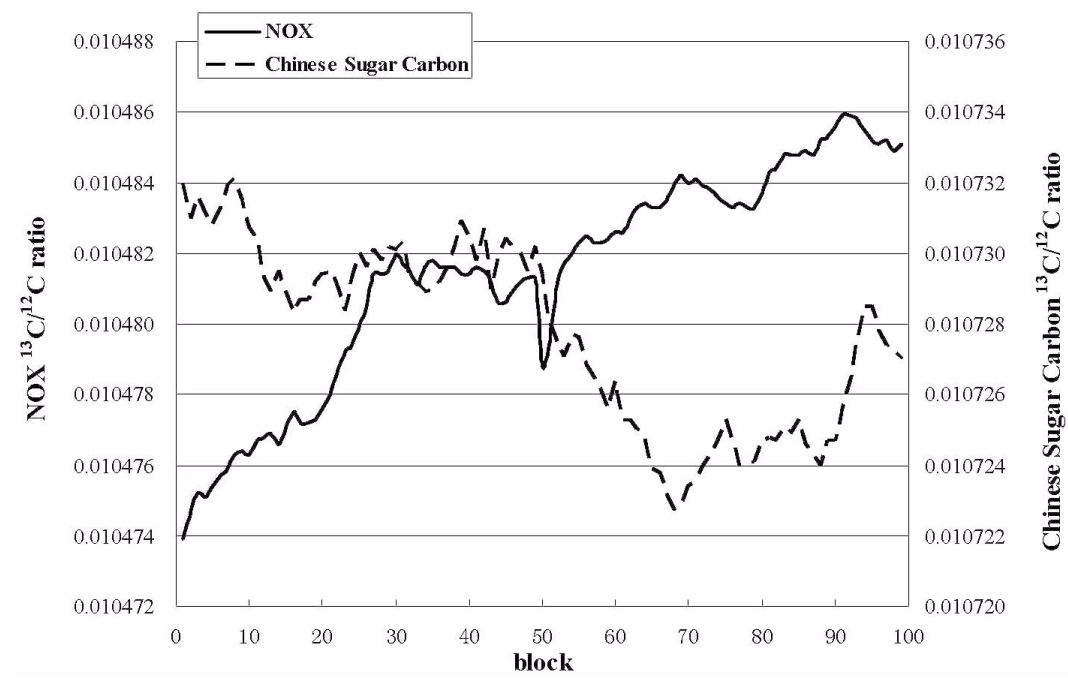

Figure 2 The ratio ${ }^{13} \mathrm{C} /{ }^{12} \mathrm{C}$ of both the NOX sample and Chinese sugar carbon changes with time in order to explore the crater effect of the ion source. Each block represents data taken in individual collection blocks with a well-defined duration of $30 \mathrm{~s}$.

Table 3 Results of the apparent crater effect tests using 2 modern samples.

\begin{tabular}{llllc}
\hline & New Oxalic acid & 225,000 counts & 450,000 counts & Change $(\%)^{\mathrm{b}}$ \\
\hline${ }^{13} \mathrm{C} /{ }^{12} \mathrm{C}$ & $\mathrm{RSD}^{\mathrm{c}}$ & $2.38 \times 10^{-4}$ & $2.98 \times 10^{-4}$ & 25.2 \\
& ${ }^{13} \mathrm{C} /{ }^{12} \mathrm{C}$ average & $1.04790 \%$ & $1.04814 \%$ & 0.023 \\
& RSD of average & $3.47 \times 10^{-5}$ & $3.01 \times 10^{-5}$ & -13.3 \\
${ }^{14} \mathrm{C} /{ }^{12} \mathrm{C}$ & RSD & $1.4 \times 10^{-2}$ & $1.35 \times 10^{-2}$ & $0.00^{\mathrm{d}}$ \\
& ${ }^{14} \mathrm{C} /{ }^{12} \mathrm{C}$ average & $1.15525 \times 10^{-12}$ & $1.15690 \times 10^{-12}$ & 0.143 \\
& RSD of average & $2.04 \times 10^{-3}$ & $1.36 \times 10^{-3}$ & \\
$\mathrm{Block}^{\mathrm{e}}$ & & 50 block & 99 block & \\
& & & & \\
\hline & Chinese sugar $\mathrm{C}^{\mathrm{f}}$ & 210,000 counts & 420,000 counts & Change $(\%)$ \\
\hline${ }^{13} \mathrm{C} /{ }^{12} \mathrm{C}$ & RSD & $1.36 \times 10^{-4}$ & $2.37 \times 10^{-4}$ & 74.3 \\
& ${ }^{13} \mathrm{C} /{ }^{12} \mathrm{C}$ average & $1.07294 \%$ & $1.07275 \%$ & 0.018 \\
& RSD of average & $1.76 \times 10^{-5}$ & $2.17 \times 10^{-5}$ & 23.3 \\
${ }^{14} \mathrm{C} /{ }^{12} \mathrm{C}$ & $\mathrm{RSD}$ & $1.68 \times 10^{-2}$ & $1.66 \times 10^{-2}$ & $2.03^{\mathrm{d}}$ \\
& ${ }^{14} \mathrm{C} /{ }^{12} \mathrm{C}$ average & $1.15866 \times 10^{-12}$ & $1.15879 \times 10^{-12}$ & 0.011 \\
\hline
\end{tabular}

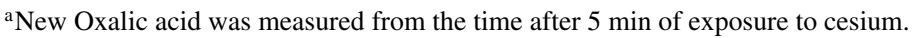

${ }^{\mathrm{b}} \mathrm{Change}$ of the data during $450,000{ }^{14} \mathrm{C}$ counts relative to during about $210,000{ }^{14} \mathrm{C}$ counts.

cRelative standard deviation.

${ }^{\mathrm{d}}$ The statistical errors for different ${ }^{14} \mathrm{C}$ total counts have been deducted.

${ }^{\text {e}}$ Time at which data was taken, having a well-defined duration of $30 \mathrm{~s}$.

${ }^{\mathrm{f}}$ Chinese sugar carbon was measured from the time after the sample was used another test of more than $1 \mathrm{hr}$. 
Another problem of the source structure that was found is a leak that occurs while pushing each holder in as shown in Figure 3. Though this does not affect machine operation, this design will be improved in future.

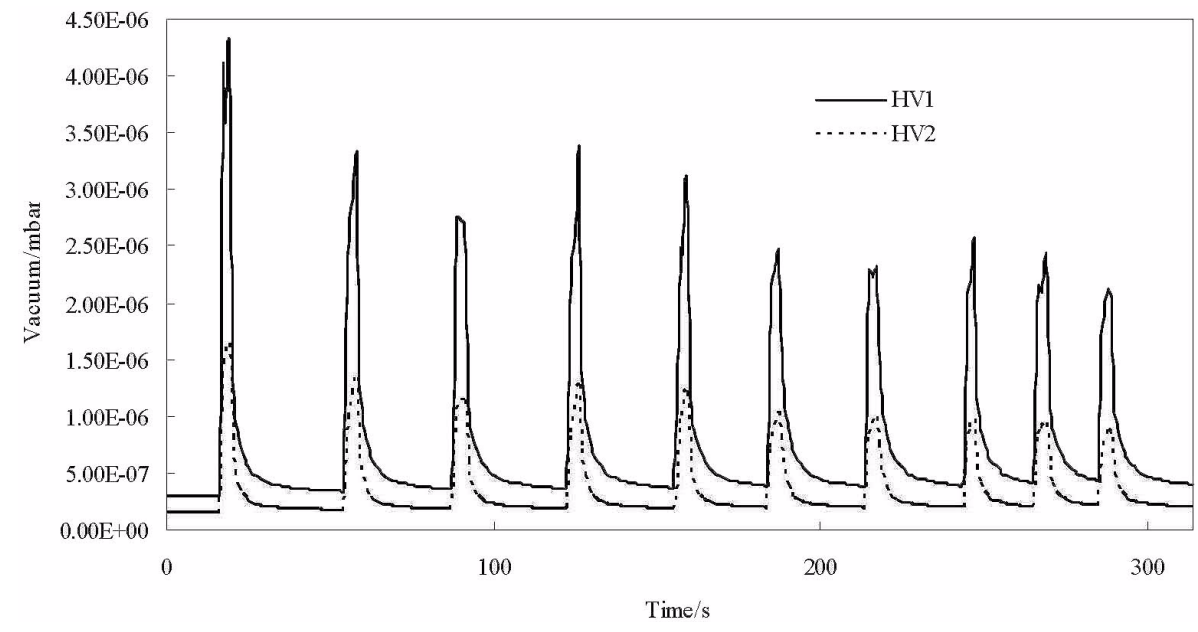

Figure 3 Changes in source vacuum while pushing in the holder. VH1 are the vacuum gauges beneath the ion source body, and $\mathrm{VH} 2$ are the vacuum gauges far from the source body.

\section{Injector with Fast Cycling, Beam Blanking Unit, and the Q-Snout}

The bouncer-based injector in the Xi' an AMS system consists of a $54^{\circ}$ electrostatic analyzer and a $90^{\circ}$ bouncer magnet, as well as the HVEE-patented "beam blanking unit" and "Q-snout." This is a special injection system developed to eliminate the shortcomings that exist in conventional bouncing systems, such as a reduction of accuracy. Like all modern AMS machines, the Xi' an AMS injector has been optimized in its bouncing setup and electronics to enable isotope ratio measurements with high precision (Klein et al. 2004).

Other than the simultaneous injection, the bouncer injection has put higher restrictions on the operation of the ion source and the whole system. Changes in the system status, like ion source instabilities or other errors, may affect the measurement of the various isotopes differently when they occur faster than the injection cycling frequency. For an accurate ratio measurement, fast cycling is required. A $100-\mathrm{Hz}$ fast cycling frequency will be routinely used in $\mathrm{Xi}$ ' an, which is regarded as sufficiently high to cope with fast source output variations (Klein et al. 2004).

A unique feature of the HVEE injector is the beam blanking unit (Klein et al. 2004), which defines the injection period for the different isotopes. During sequential switching between isotopes, the magnet chamber voltage requires some time to settle because the pulsing bouncer voltage is as high as $2-3 \mathrm{kV}$ with a long rising time of $50-100 \mu \mathrm{s}$. The voltage variation during the settling time will influence the final precision. Such a negative effect of the settling process is eliminated by using the beam blanking unit located between the bouncer magnet and accelerator entrance. This unit is a steerer acting as a fast switch with only a 50-ns rising time of the pulsing voltage, owing to the fact that the pulsing voltage on the unit is as low as $300 \mathrm{~V}$. (Figure 4). During the bouncer voltage settling time, the $300-\mathrm{V}$ unit voltage is on to deflect the beam out of the beam patch, and during the bouncer, voltage is stable and the unit voltage is off to let the beam pass into the accelerator. 


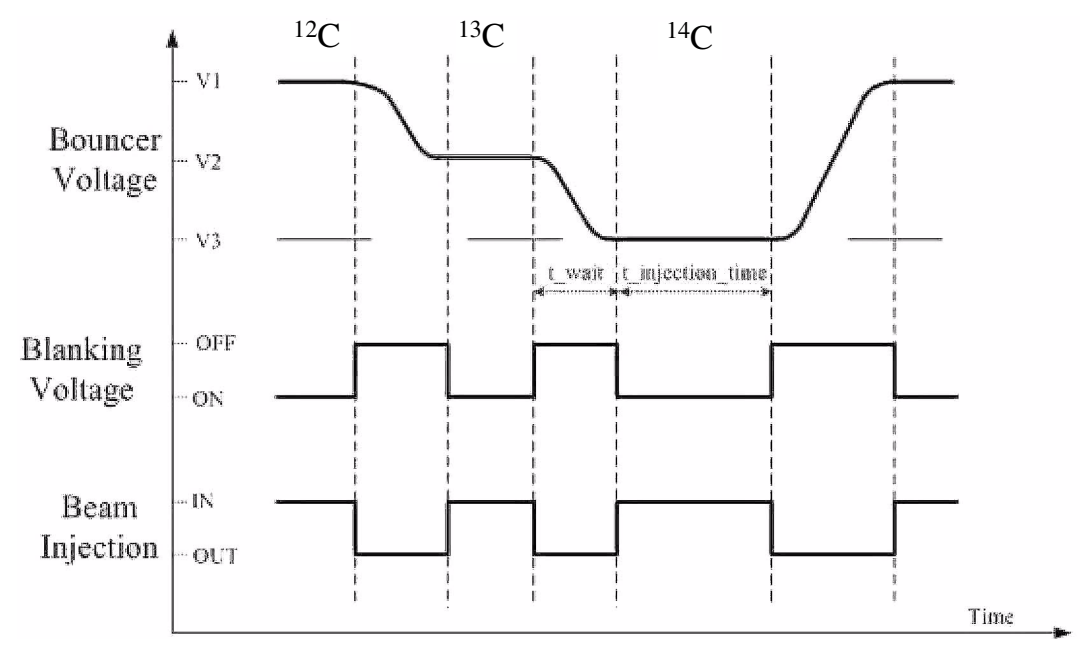

Figure 4 Principle of the beam blanking unit. The beam blanking unit, located between the bouncer magnet and accelerator entrance (see text for details of operation).

Another specific feature of the injector is that the injection energy of the Xi' an AMS is only $35 \mathrm{keV}$ (Purser et al. 1992), which makes all electrostatic and magnetic parameters or geometric dimensions smaller than ones in AMS systems with 70-keV injection energy (Priller et al. 1997). However, 35$\mathrm{keV}$ ions will be overfocused at the entrance of the accelerator and lost in the internal wall of the low-energy acceleration tube because the shape of the equipotential surfaces at that location are convexed outward. To correct this, a Q-snout (Mous et al. 1995) (Figure 5) is assembled at the entrance of the low-energy acceleration tube, which gradually increases the energy of the injected ions up to $\sim 85 \mathrm{keV}$ and corrects for the overfocusing of ions in order to appropriately focus them on to the stripper channel (Gottdang, personal communication, 2002).

\section{Acceleration Tube With Combined Magnetic and Electrostatic Suppression}

The 3MV Tandetron is a Dynamitron-type tandem accelerator. The power supply is a solid-state, high-frequency, parallel-fed Cockroft Walton operating at $\sim 35 \mathrm{kHz}$ (Purser 1992). In both the preshipment and the acceptance tests, only 1 test during which the $3 \mathrm{MV}$ terminal voltage was maintained without sparking for $4 \mathrm{hr}$ was checked without the beam on.

The X-ray dose is very low, well below $2 \mu \mathrm{S} / \mathrm{hr}$ at $1 \mathrm{~m}$ from the tank wall during operation and the beam on, which is attributed to the design of the acceleration tubes. To significantly reduce the $\mathrm{X}$ ray radiation, both small, permanent magnets and declined electrodes (Purser 1992) are spirally arranged inside the tubes to remove electrons and background particles that have been produced by charge changing and sputtering from the tube electrodes. However, the magnetic suppression is mass-dependent, which will make particles with different masses have different trajectories and suffer from different electrostatic forces in the declined electrostatic field, which alone is originally mass-independent. Hence, the combined magnetic and electrostatic suppression might induce fractionation. Gottdang (personal communication, 2006) mentions that the combined suppression has been considered in the design calculation of the tube, and also the internal diameter of the tube electrodes is designed to be varied following the shape of the beam envelope. 


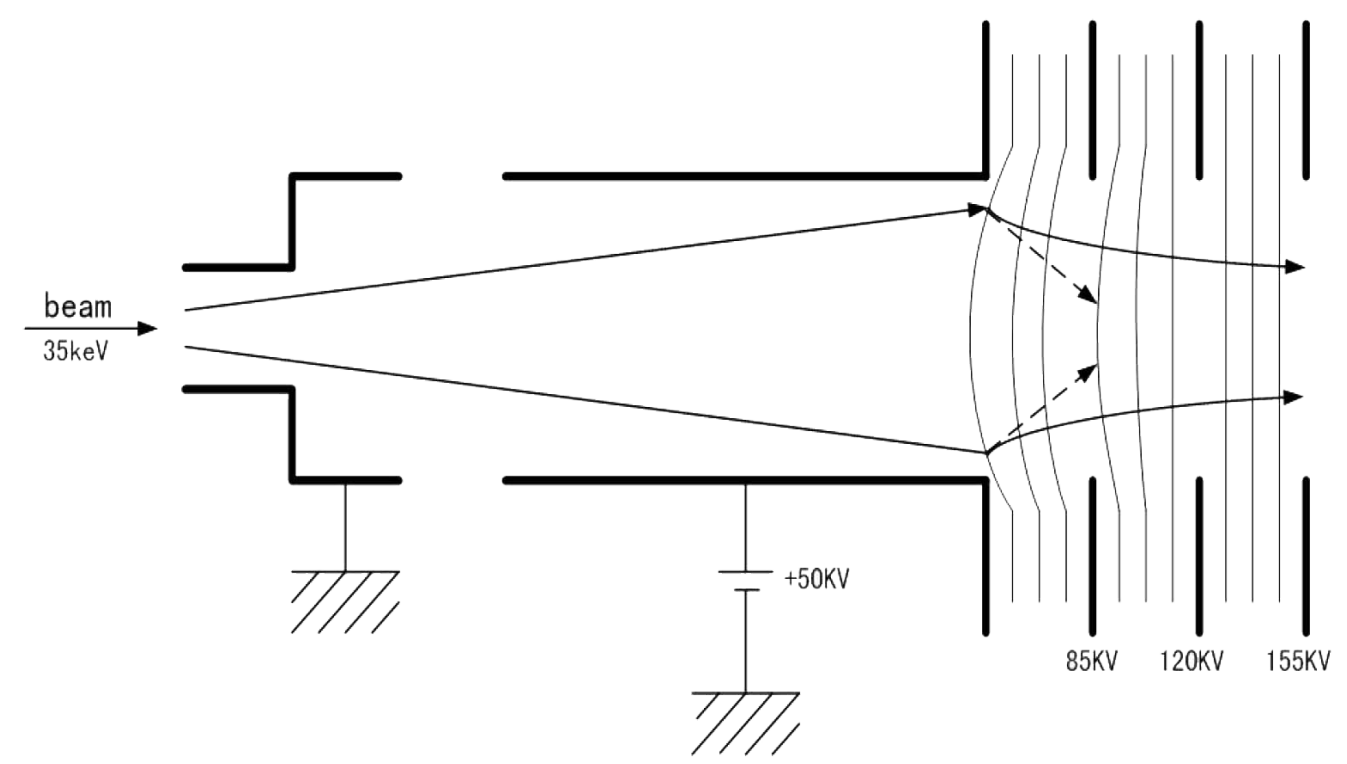

Figure 5 Principle of the Q-snout. Ions with $35 \mathrm{keV}$ will be overfocused at the entrance of the accelerator and lost in the internal wall of the low-energy acceleration tube because the shape of the equipotential surfaces at that location are convexed outward.

\section{Post Analyzers and the Slit Stabilization}

The post-acceleration system is a magnetic-electrostatic-magnetic high-resolution mass spectrometer. The main component is the $115^{\circ}$ magnet, and its maximum magnetic field is $1.144 \mathrm{~T}$. However, the estimated magnetic field required for $3 \mathrm{MV}{ }^{129} \mathrm{I}^{+5}$ acceleration is about $1.14 \mathrm{~T}$, so these studies will be performed at $2.5 \mathrm{MV}$.

The $65^{\circ}$ electrostatic analyzer has a very large curvature radius $(1700 \mathrm{~mm})$, so it is highly energy dispersive and causes the separation between ${ }^{10} \mathrm{Be}^{+3}$ and ${ }^{10} \mathrm{~B}^{+3}$ ions to be $3.6 \mathrm{~cm}$ in front of the detector (Mous, personal communication, 2002) after passing through a $500-\mathrm{nm} \mathrm{Si}_{3} \mathrm{~N}_{4}$ foil located in front of the $65^{\circ}$ electrostatic analyzer. This plays an effective role in reducing the level of scattered ${ }^{10} \mathrm{~B}^{+3}$ during counting.

The original motivation for "slit stabilization" after the high-energy analyzing $\left(115^{\circ}\right)$ magnet is to increase the stability of the beam energy by stabilizing the terminal voltage, which is controlled by the feedback of the slit error signals induced by the beam of the stable isotopes. Such a stabilizing function can only be successful when the slit error signals are induced due to a change of the terminal voltage. If the slit error signals are induced due to a change of some parameter, the terminal voltage would be adjusted to compensate this parameter change and to fix the position of the stable isotope beam inside the slit system. This phenomenon was discovered in the course of performing all the precision tests when the maximum fluctuations of the terminal voltage were $\sim 4-6 \mathrm{kV}$, ranging within $2498 \sim 2503 \mathrm{kV}\left({ }^{14} \mathrm{C}\right), 2499 \sim 2503 \mathrm{kV}\left({ }^{10} \mathrm{Be}\right), 2599 \sim 2605 \mathrm{kV}\left({ }^{26} \mathrm{Al}\right)$, and $2499 \sim 2503 \mathrm{kV}\left({ }^{129} \mathrm{I}\right)$, though the required precisions were all obtained. Therefore, the real function of the slit stabilization is to precisely measure the beam currents of the stable isotope and to improve the measurement of the isotope ratio rather than only to stabilize the terminal voltage. If the terminal voltage changes, the slit stabilization will be more effective functioning in the simultaneous injection mode than in the sequential injection mode. The reason is that the slit error signal induced by the stable isotope 
beam is picked up at $100 \%$ of the time in the simultaneous injection mode, whereas at only $1 \%$ of the time of each cycling in the sequential injection mode. Nevertheless, the slit stabilization is still functioning in our AMS system, owing to the fact that our injection system is working with a fast cycling of $100 \mathrm{kHz}$.

"Flat top" transmission is carried out in the HVEE-designed Xi' an 3MV AMS by enlarging the diameter of the acceleration tube, thus making the diameter of the stripper channel twice the size of the beam spot (Purser 1988), opening the adjustable slits as wide as possible so as not to intercept the ions, and modeling all of the electric and magnetic parameters using the "Trace" program. As a result, the fractionation has been minimized in the HVEE design when a minor fluctuation of the electric or magnetic parameter occurs. This design even allows for the electrostatic settings to remain the same when analyzing negative molecular ions, such as $\mathrm{BeO}^{-}$, where the energy difference between the ${ }^{10} \mathrm{Be}^{+3}$ and ${ }^{9} \mathrm{Be}^{+3}$ ions is as high as $0.73 \%$.

\section{CONCLUSION}

Preliminary tests have convinced us that the Xi' an 3MV AMS can already serve our purposes at a terminal voltage of 2.5-2.6 MV. We hope to improve the background of beryllium, which depends on some factors, including sample preparation. The tests show that a bouncer-based AMS can reach the same high ${ }^{14} \mathrm{C}$ precision as a recombinator-based AMS, and the precision of ${ }^{10} \mathrm{Be},{ }^{26} \mathrm{Al}$, and ${ }^{129} \mathrm{I}$ also have reached levels better than we expected. Further tests will explore the maximum potential of the facility for ${ }^{129} \mathrm{I}^{+5}$ measurements and will measure the 3 nuclides ${ }^{10} \mathrm{Be},{ }^{26} \mathrm{Al}$, and ${ }^{129} \mathrm{I}$ by increasing the terminal voltage towards $3 \mathrm{MV}$. Finally, there are some improvements needed, such as the last slit in front of the detector, which will be changed into an adjustable slit to better enable multi-element analyses.

\section{ACKNOWLEDGMENTS}

The authors are deeply indebted to Prof Yongxiang Lu, Prof Yiyu Chen, Prof Jiayang Li, Prof Zhisheng An, Prof Nanning Zheng, Dr Xu Ping, and Dr Tian Dongsheng for their strong support and supervision over all aspects of this project. We are also grateful to Profs Maobai Chen, Liping Yang, Dr Xiaolei Zhao, and Prof Zhenhao Liu for their concrete technical support and advice. Many wellknown AMS experts have provided us with valuable suggestions and technical information in our planning stage; we would like to express our sincere acknowledgement to Profs and Drs ZY Guo, KX Liu, CD Shen, SS Jiang, W Kutschera, A Priller, D Donahue, AJT Jull, G Burr, W Beck, M Nadeau, G Raisbeck, T Kitamura, and E Cottereau. Finally, we would like to thank the physicists at HVEE; D Mous, A Gottdang, and K Klein for their excellent design; and J Bergen, SA Miedema, and MC Sorby for their careful and skilled work on installation and testing. This project is supported by funding from the Chinese Academy of Sciences, Ministry of Education, Ministry of Science and Technology, and NSFC40531003, 40523002 \& 40121303, and NBRPC2004CB720200 grants.

\section{REFERENCES}

Aramaki T, Mizushima T, Mizutani Y, Yamamoto T, Togawa O, Kabuto S, Kuji T, Gottdang A, Klein M, Mous DJW. 2000. The AMS facility at the Japan Atomic Energy Research Institute. Nuclear Instruments and Methods in Physics Research. B 172:1823.

Calcagnile L, Quarta G, D'Elia M, Gottdang A, Klein M, Mous D W. 2004. Radiocarbon precision tests at the
Lecce AMS facility using a sequential injection system. Nuclear Instruments and Methods in Physics Research B 215:561-4.

Gottdang A, Mous DW. 1997. The novel HVEE multi-element AMS system. Nuclear Instruments and Methods in Physics Research B 123:163-6.

Gottdang A, Mous DW. 1999. Characteristics of the HVEE 3MV multi-element AMS system. In: Duggan 
JL, Morgan IL, editors. Proceedings of Application of Accelerators in Research and Industry. CP475. Melville, USA: American Institute of Physics. p 6526.

Klein M, Mous DJW, Gottdang A. 2004. Fast and accurate sequential injection AMS with gated Faraday cup current measurement. Radiocarbon 46(1):77-82.

Mous DJW, Gottdang A, Van den Brock R, Haitsma RG. 1995. Recent developments at HVEE. Nuclear Instruments and Methods in Physics Research B 99:697700.

Mous DJW, Fokker W, van den Broek R, Koopmans R, Bronk Ramsey C, Hedges REM. 1998. An ion source for the HVEE ${ }^{14} \mathrm{C}$ isotope ratio mass spectrometer for biomedical applications. Radiocarbon 40(1):283-8.

Nadeau M-J, Schleicher M, Grootes PM, Erlenkeuser H, Gottdang A, Mous DJW, Sarnthein JM, Willkomm H. 1997. The Leibniz-Labor AMS facility at the Christian-Albrechts University, Kiel, Germany. Nuclear Instruments and Methods in Physics Research B 123: 22-30.

Nakamura T, Niu E, Oda H, Ikeda A, Minami M, Takahashi H, Adachi M, Pals L, Gottdang A, Suya N. 2000. The HVEE Tandetron AMS system at Nagoya Univer- sity. Nuclear Instruments and Methods in Physics Research B 172:52-7.

Priller A, Golser R, Hille P, Kutschera W, Rom W, Steier P, Wallner A, Wild E. 1997. First performance tests of VERA. Nuclear Instruments and Methods in Physics Research B 123:193-8.

Purser KH. 1992. A high throughput ${ }^{14} \mathrm{C}$ accelerator mass spectrometer. Radiocarbon 34(3):458-67.

Purser KH, Smick T. 1988. A third generation ${ }^{14} \mathrm{C}$ accelerator mass spectrometer. Nuclear Instruments and Methods in Physics Research B 35:284-91.

Purser KH, Smick TH, Purser RK. 1990. A precision ${ }^{14} \mathrm{C}$ accelerator mass spectrometer. Nuclear Instruments and Methods in Physics Research B 52:263-8.

van der Plicht J, Aerts A, Wijma S, Zondervan A. 1995. First results from the Groningen AMS facility. Radiocarbon 37(2):657-61.

Zhou WJ, Liu L, Zhao XL, Lu XF, Wu ZK, Xi G, Yang LP, Chen MB. Forthcoming. Xi' an-AMS: a multi-element system at the Xi' an AMS Center. Proceedings of the 10th International Conference on Accelerator Mass Spectrometry. Nuclear Instruments and Methods in Physics Research B. 